\title{
CHANGE IN NUMBERS AND NESTING ECOLOGY OF THE GYRFALCON IN THE YAMAL PENINSULA, RUSSIA, FROM 1981 TO 2010
}

\author{
Svetlana Mechnikova ${ }^{1}$, Michael Romanov², and Nikolay KudryavtseV ${ }^{3}$
}

${ }^{1}$ State Darwin Museum, Vavilova street, 57, Moscow 117292, Russia

E-mail: mechnikova@yandex.ru

${ }^{2}$ Institute of Mathematical Problems of Biology, Institutskaya street, 4, Pushchino 142290, Moscow region, Russia

E-mail: michael_romanov@inbox.ru

${ }^{3}$ Moscow State Pedagogical University, Postgraduate Study in Zoology, Malaya Pirogovskaya street, 1, Moscow, Russia

E-mail: nikolay63@yandex.ru

\begin{abstract}
On the Yamal Peninsula (NW Siberia, Russia), the Gyrfalcon (Falco rusticolus) has been studied for more than 30 years. In this paper we summarize data on the dynamics of its nesting density and ecology during 1981-2010. Nesting density was $0.2-1.6$ active nests per 1,000 $\mathrm{km}^{2}$, or $0.3-2.0$ active nests per $100 \mathrm{~km}$ of river valleys. The density varied between years, with the maximum occurring in the mid-1990s and the minimum in the mid- to late-2000s. We suggest that the population decrease in the 2000 s was caused by a decrease of breeding success and by robbing of Gyrfalcon nests for falconry. By our estimation, the contemporary population on the Yamal Peninsula consists of 15-45 annually breeding pairs.
\end{abstract}

Relatively few cliff sites occur there, and most Gyrfalcons used tree nests (more than $80 \%$ of nesting attempts). Average brood size was 2.58 fledglings per active nest $(\mathrm{n}=76)$, and higher in rock nests than in tree nests: $3.25(\mathrm{n}=16)$ and $2.40(\mathrm{n}=60)$, respectively. Brood size in tree nests decreased from 2.91 fledglings per active nest $(n=22)$ in $1981-1992$ to 1.94 in 2005-2010 $(n=17)$. Until the 1990s, Gyrfalcons occupied almost exclusively large tree nests (more than $80 \mathrm{~cm}$ in diameter) built by White-tailed Eagles (Haliaeetus albicilla). From the 1990s, they began more frequently to occupy medium- and even small-sized (less than $55 \mathrm{~cm}$ ) tree nests built by Common Ravens (Corvus corax), Rough-legged Buzzards (Buteo lagopus), and even Hooded Crows (Corvus cornix), though the number of available large tree nests had not decreased. Nest size influences chick survival: small nests are destroyed more often than large nests. Average brood size was 3.0 in large tree nests $(n=34), 2.43$ in medium-sized nests $(n=21)$, and 1.6 in small nests $(n=15)$. We suggest that the Gyrfalcon's preference for small nests in recent years may be caused by the consolidation of the snow layer on the nest surface in spring as a result of unstable weather conditions - thaws interchanging with frosts, that may be connected to climate change. Gyrfalcons unable to remove the solidified snow from a large nest are forced to occupy a smaller one. As a provisional measure to reduce chick mortality, we began to install artificial nest-boxes with sheds on trees. Received 29 December 2010, accepted 10 May 2011. 
Mechnikova, S., M. Romanov, And N. Kudryavtsev. 2011. Change in numbers and nesting ecology of the Gyrfalcon in the Yamal Peninsula, Russia, from 1981 to 2010. Pages 205-212 in R. T. Watson, T. J. Cade, M. Fuller, G. Hunt, and E. Potapov (Eds.). Gyrfalcons and Ptarmigan in a Changing World, Volume II. The Peregrine Fund, Boise, Idaho, USA. http://dx.doi.org/ 10.4080/gpcw.2011.0220

Key words: Gyrfalcon, Falco rusticolus, brood size, nest size, climate change.

StUdies OF THE BIOLOGY OF THE GyRFALCON (Falco rusticolus) in Russia were scarce until recently (Potapov and Sale 2005, Koskimies 2006). On the southern portion of the Yamal Peninsula, observation of Gyrfalcons began in 1973, when V. V. Kucheruk and colleagues found the first nest of this species on the Shchuch'ya River (Kucheruk et al. 1975). From 1974 to 1985 , V. N. Kalyakin annually monitored raptor populations, including Gyrfalcons, and studied their ecology in the basin of this river. He mainly focused attention on diet, food relationships, and role of raptors in tundra ecosystems (Kalyakin and Vinogradov 1981, Kalyakin 1983, 1989). In the same years, data on distribution and breeding of Gyrfalcons on the Khadyta River were collected by zoologists of the Institute of Ecology of the Ural Science Centre of the Science Academy of the Soviet Union (Danilov et al. 1984).

Our studies of raptors, including Gyrfalcons, began in the Yamal Peninsula in 1981. We mainly studied their nesting ecology, nesting density, and breeding success. Some results of our Gyrfalcon study in this area have been earlier published (Mechnikova and Kudryavtsev 2008, Mechnikova 2009, Mechnikova et al. 2010). In this paper we summarize trends in the dynamics of the population, nesting ecology, and breeding success of this species from 1981-2010.

\section{Methods}

The study area (about $5800 \mathrm{~km}^{2}$ ) is located in the southern portion of the Yamal Peninsula, NW Siberia, Russia $\left(66^{\circ} 50^{\prime}-67^{\circ} 40^{\prime} \mathrm{N}, 67^{\circ} 30^{\prime}\right.$ $-70^{\circ} 00^{\prime} \mathrm{E}$ ) (Figure 1). The primary part of the study area (about $2600 \mathrm{~km}^{2}$ ) was the Shchuch'ya River basin. We worked there 19 summer seasons (1981-1984, 1986, 19881992, 1996, 2000, 2005-2010); two seasons (1997 and 2005) were also spent on the Hadyta River.

The study area lies at the boundary between the southern (shrubby) tundra and the northern forest-tundra. Sparse larch (Larix sibirica) forests grow along river valleys, sometimes with spruce (Picea obovata) and mountain birch (Betula tortuosa), which form bands from several $\mathrm{m}$ to $1.5 \mathrm{~km}$ wide. Only here and there do larch forests expand to watersheds, as the latter are mostly covered with tundra growth. The terrain is mainly flat or slightly hilly, with maximum altitudes of about $200 \mathrm{~m}$ above sea level. Occasional rocky cliffs of up to $30 \mathrm{~m}$-high occur in the northern part of the Shchuch'ya River basin. On the whole, however, rocks account for only $16-17 \mathrm{~km}$ of the approximately $500 \mathrm{~km}$ of river valleys surveyed. Intensive, nomadic, year-round Reindeer (Rangifer tarandus) farming takes place in the area, except in July and August, when Reindeer graze farther to the north.

Our basic method was to survey nest-suitable biotopes along boating or walking routes, and to observe and record active Gyrfalcon nests, territorial individuals, and flying broods. We visited nests in June and July when there were large nestlings or fledglings. We recorded a total of 64 breeding attempts. We also received information on about 31 nests from other researchers who worked in the same area during 1981-2001. These researchers included M. Galich, A. Leonov, P. Luzan, S. Rupasov, B. Russo, A. Sharikov, A. Tishechkin, and A. Tyunin (pers. comm.). We obtained additional information from V. N. Kalyakin for the period 1973-1980 (pers. comm.). 


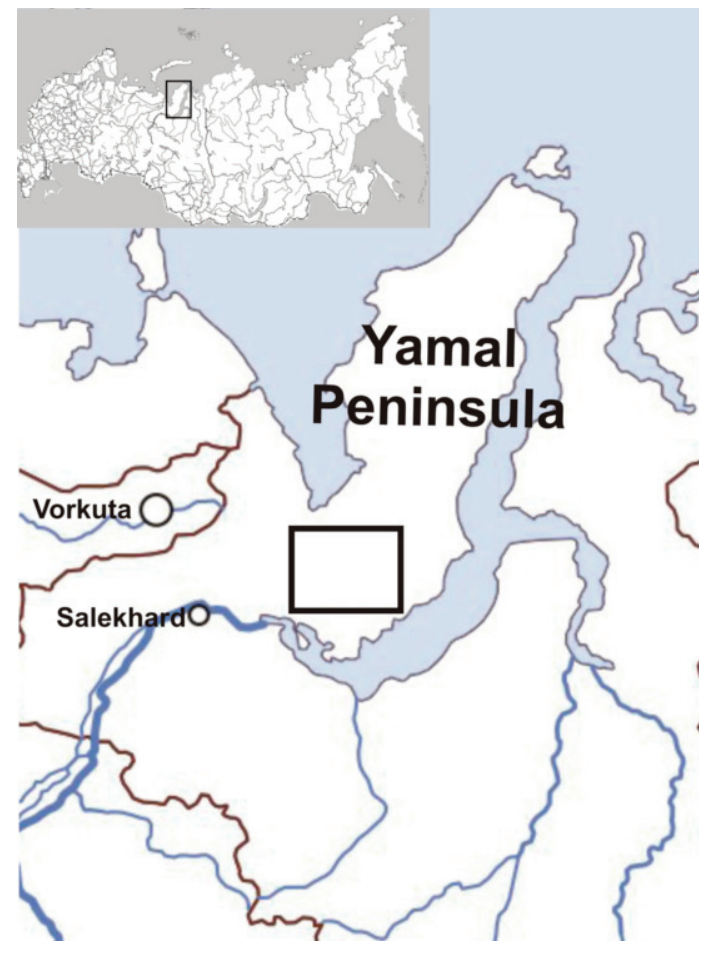

Figure 1. Study area.

We used an index of "linear density" for an estimation of Gyrfalcon abundance: the number of nests per $100 \mathrm{~km}$ of river valley, since Gyrfalcon nesting biotopes (rocks and light forests) are distributed very irregularly in the study area, and the overwhelming majority of nests are found in river valleys (see Results). We estimated abundance of Willow Ptarmigan (Lagopus lagopus) only visually and approximately, using the following rank scale: $1=$ very low, $2=$ low, $3=$ average, $4=$ high, $5=$ very high.

\section{Results}

Gyrfalcons inhabit only the southern part of the Yamal Peninsula to about $68^{\circ} \mathrm{N}$, as suitable nesting habitats are absent further north. They usually nest in trees or, less often, on rocks (only 18 (19\%) of 95 cases), as suitable cliffs are scarce in the region. In two cases, Gyrfalcons bred on wooden triangulation towers, but from the 1990s, all towers were broken. Gyrfalcons usually occupied nests built by Common Ravens (Corvus corax), White-tailed Eagles (Haliaeetus albicilla), Rough-legged Buzzards (Buteo lagopus), and very seldom they occupied nests built by Golden Eagles (Aquila chrysaetos) and Hooded Crows (Corvus cornix). All these species built nests in trees, but only Rough-Legged Buzzards and Ravens built them on rocks.

We found approximately 30 nesting territories on the study area. Their distribution was very irregular: 25 territories (83\%) were within the Shchuch'ya River basin in an area of about $2600 \mathrm{~km}^{2}$ where nesting habitat of this species predominantly occurred; $95 \%$ of the nests were found along river valleys.

Nesting density in the Shchuch'ya River basin was typically one-to-four active nests per $1,000 \mathrm{~km}^{2}$, and only locally in some years it reached eight nests per $1,000 \mathrm{~km}^{2}$. Overall density on all study areas was less than two nests per $1,000 \mathrm{~km}^{2}$ (Table 1 ). The usual density was one-to-two pairs per $100 \mathrm{~km}$ of river valleys within suitable biotopes, and a maximum linear local density of five pairs per 100 km (in 1995 and 1996). Minimal inter-pair distance was $1.6 \mathrm{~km}$ (in 1996), but usually it was no less than $4 \mathrm{~km}(12.1 \mathrm{~km}$ on average, $\mathrm{n}=72$ comparisons). We estimated total numbers on the Yamal at about 15-45 annually nesting pairs (Mechnikova 2009).

Nesting density varied greatly from 19812010. The maximum occurred in the mid1990s, and the minimum in the 2000s (Figure 2 ). We did not detect a correlation between the numbers of Gyrfalcons and ptarmigan, possibly because our visual approximation of ptarmigan abundance was inexact, but it is interesting to note that Gyrfalcon breeding numbers remained relatively slight during the 2000 s despite an apparent increase in ptarmigan abundance in the mid-2000s to the level comparable to that observed in the 1980s. 
Table 1. Nesting density of Gyrfalcons on the study area.

\begin{tabular}{|c|c|c|c|c|}
\hline & \multicolumn{4}{|c|}{ Time periods } \\
\hline & \multicolumn{2}{|c|}{$1986-1997$} & \multicolumn{2}{|c|}{ 2000-2009 } \\
\hline & Limits & Average & Limits & Average \\
\hline \multicolumn{5}{|c|}{ Shchuch'ya River basin (2600 km², 25 nesting territories) } \\
\hline Density (active nests per 1000 km²) & $1.8-4.0$ & 3.0 & $0.4-3.0$ & 2.2 \\
\hline Linear density (active nests per $100 \mathrm{~km}$ of rivers) & $1.3-4.3$ & 2.6 & $0.3-2.0$ & 1.4 \\
\hline \multicolumn{5}{|l|}{ All study areas (5800 km², 30 nesting territories) } \\
\hline Density (active nests per 1000 km²) & - & - & $0.2-1.6$ & 1.2 \\
\hline
\end{tabular}

Table 2. Difference of average brood size in Gyrfalcon nests of different types and sizes.

\begin{tabular}{|c|c|c|c|c|c|}
\hline & \multicolumn{5}{|c|}{ Nest disposition and size } \\
\hline & \multirow{2}{*}{ on rocks } & \multicolumn{4}{|c|}{ on trees } \\
\hline & & large & medium-sized & small & average \\
\hline \multirow[t]{2}{*}{ Average brood size (fledglings per brood) } & 3.25 & 3.0 & 2.43 & 1.6 & 2.4 \\
\hline & $(n=16)$ & $(n=34)^{*}$ & $(n=21)$ & $(n=15)$ & $(n=60)$ \\
\hline
\end{tabular}

*Including data from V. N. Kalyakin for 1973-1980 (pers. comm.).

Table 3. Number of large nests on the 130-km segment of the Shchuch'ya River.

\begin{tabular}{lccccccccccccc}
\hline & $\mathbf{1 1}$ & \multicolumn{11}{c}{ Years of observation } \\
& $\mathbf{8 6}$ & $\mathbf{8 8}$ & $\mathbf{8 9}$ & $\mathbf{9 0}$ & $\mathbf{9 1}$ & $\mathbf{9 6}$ & $\mathbf{0 0}$ & $\mathbf{0 5}$ & $\mathbf{0 6}$ & $\mathbf{0 7}$ & $\mathbf{0 8}$ & $\mathbf{0 9}$ & $\mathbf{1 0}$ \\
\hline $\begin{array}{l}\text { No. of large nests total } \\
\begin{array}{l}\text { No. of active nests of } \\
\text { the White-tailed Eagle }\end{array}\end{array}$ & 18 & 15 & 12 & 14 & 13 & 17 & 11 & 18 & 20 & 19 & 20 & 19 & 17 \\
\hline
\end{tabular}

Average brood size in Gyrfalcons was 2.68 fledglings per successful nest $(n=73)$ and was similar to data reported for other regions (Clum and Cade 1994, Cade et al. 1998, Potapov and Sale 2005). However, brood size differed in nests of different types and sizes (Table 2). Average brood size in tree nests decreased during the study period (Figure 3) (linear regression, $\mathrm{P}<0.05)$. According to data from V. N. Kalyakin (1983), there were 3.3 fledglings per brood in tree nests $(n=22)$ in 1973-1982. According to our data, there were 2.91 fledglings per brood in tree nests during 1981-1992 $(\mathrm{n}=22), 2.27$ during 1995-2001 $(n=21)$, and 1.94 during 2005-2010 $(n=17)$.

Until the 1990s, including data from V. N. Kalyakin for 1973-1980 (pers. comm.), Gyrfalcons almost exclusively occupied large tree nests (more than $80 \mathrm{~cm}$ in diameter) built by 


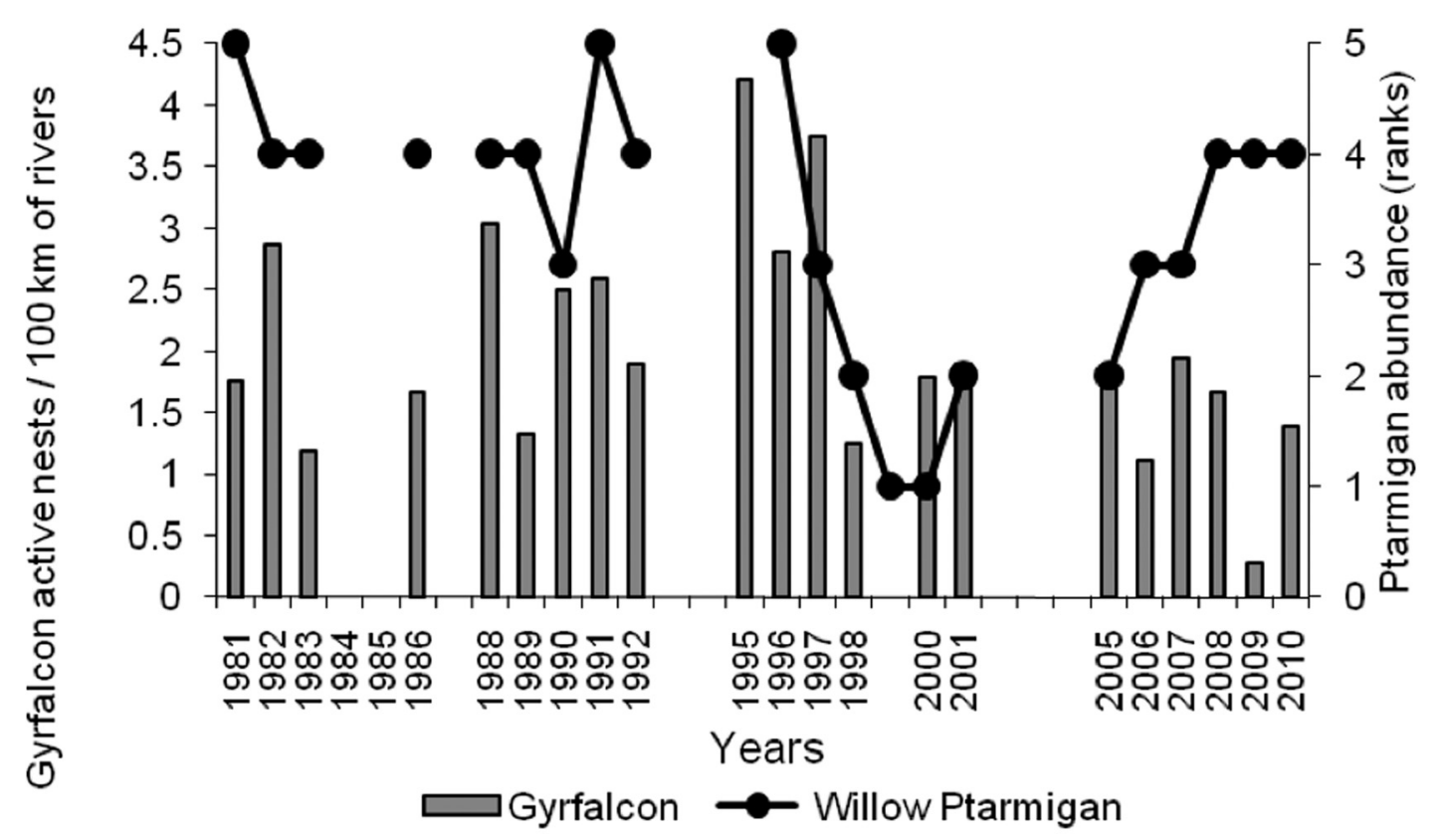

Figure 2. Relationship of linear nesting density of the Gyrfalcons in the Shchuch'ya River basin and annual abundance estimates of Willow Ptarmigan.

White-tailed Eagles. From the 1990s, Gyrfalcons increasingly occupied medium-sized and even small (less than $55 \mathrm{~cm}$ ) tree nests built by Rough-legged Buzzards or Ravens, while the occupancy of large nests decreased (Figure 4). At least four cases of using old nests of Hooded Crows were recorded in this later period, and that is very unusual for Gyrfalcons (Potapov and Sale 2005). Numbers of large nests built by White-tailed Eagles did not decrease (Table 3).

\section{Discussion}

V. N. Kalyakin (Kalyakin and Vinogradov 1981, Kalyakin 1998) regarded the Gyrfalcon as a common species on the Yamal Peninsula, and estimated its population at not less than 4550 breeding pairs, much higher than our current estimate of 15-45 pairs. The earlier estimate was based on the high nesting density of this species in the middle part of the Shchuch'ya River basin from the late 1970s to the mid1990s (up to 11 nesting territories or 7 breeding pairs in an area of $900 \mathrm{~km}^{2}$ ). But such high density was known only locally and only in single years. In estimating the regional population, it is necessary to consider that nesting Gyrfalcons are very scarce (or absent) on the east macroslope of the Polar Ural Mountains and on the Lower Ob' River, and that the species' nesting biotopes are distributed very irregularly. It is necessary also to take into account that its present-day density is slight even in areas with the most favorable conditions.

Reasons for Gyrfalcon population decrease in the 2000s may be complex. A primary reason may be the Willow Ptarmigan decrease from the late-1990s to the early-2000s. As shown in papers by O. Nielsen (Nielsen 1999), numerical fluctuations of Gyrfalcons can lag 2-3 years behind those of ptarmigan. However, in the mid-2000s, Willow Ptarmigan populations on the Southern Yamal increased to a level similar to that seen in the 1980s, whereas Gyrfalcon densities remained relatively low. A possible reason for the decrease in Gyrfalcon 


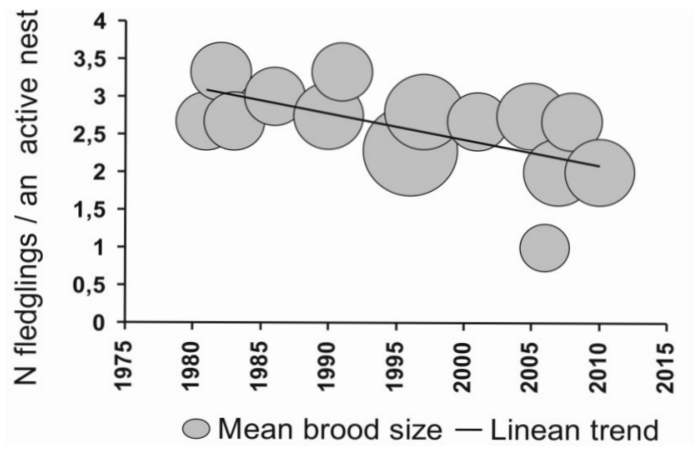

Figure 3. Dynamics of the average brood-size of the Gyrfalcon in 1981-2010. Circle size corresponds to number of nests.

productivity from the mid-1990s was a simultaneous decrease in nest success and broodsize associated with transition to using smaller nests in trees. We used a log-linear analysis of a three-dimensional contingency table to test this hypothesis (Mechnikova et al. 2010). Results supported the idea that transition to using smaller nests reduced breeding success of the Gyrfalcon. Our field observations confirmed that small nests were often fragile and tended to crumble during the period of nestling development, and nestlings and fledglings in these nests were often lost. Similar observations were made by J. Obst (1994) in the western Canadian Arctic.

It is difficult to explain what caused the transition to the use of smaller nests by Gyrfalcons. It is unlikely that large nests were in short supply, as their numbers have not decreased (Table 3). On the contrary, large nests became more numerous as the White-tailed Eagle population on the Yamal Peninsula increased from the late-1990s (Mechnikova 2009). As data from V. N. Kalyakin (pers. comm.) and our observations show, Gyrfalcons tend to prevail in competition with White-tailed Eagles. For example, in 2008, a Gyrfalcon pair confiscated a just-built nest from a White-tailed Eagle pair.

We suspect that Gyrfalcons now occupy large nests less often than previously because these nests are less accessible to them in spring. It is known that accessibility and quality of nests are major factors determining the distribution and abundance of this species (Morozov 2000, Koskimies 2006). Gyrfalcons prefer to occupy nests on rocks which are protected by overhangs (Clum and Cade 1994, Cade et al. 1998, Potapov and Sale 2005) because they accumulate less snow. Tree nests are available for Gyrfalcons only if birds can easily clean them by removing snow.

Climate change can influence snow conditions. Warming in recent years has increased the frequency of alternation between frosts and thaws, and snow on nests has become very compact. Thus, when Gyrfalcons are unable to remove the solid snow 'cap' from a large nest, they are relegated to a smaller one, which is easier to clear of snow. This hypothesis is supported by some observations. In years when weather was characterized by thaws with rains followed by frosts (for instance, 1992, 2006, 2008) Gyrfalcons occupied not a single old large tree nest.

Anthropogenic factors have also affected Gyrfalcons on the Yamal Peninsula. On the one hand, mortality associated with Arctic Fox (Vulpes lagopus) trapping has declined in recent years. Prior to the mid-1990s, many Gyrfalcons died in Arctic Fox traps in winter (Kalyakin 1989).

On the other hand, an increase in the human population and numbers of domestic Reindeer occurred there in the 1990s-2000s and has increased disturbance to Gyrfalcons during the incubation and brooding period. For instance, a nesting territory near a Reindeer roaming track annually incurs clutch loss. Another probable negative factor may be robbing of nests and the catching of adult Gyrfalcons for falconry. From the 1990s, when the new route to the Yamal gas deposit was built, the Shchuch'ya River basin became more accessible to poachers. We have information about cases of illegal collecting of Gyrfalcon 
nestlings in 2000, eggs in 2009, and of the catching of young birds in 2005 .

As a provisional measure to reduce chick mortality and maintain the Gyrfalcon population on the Yamal Peninsula, we are installing artificial nest-boxes with sheds similar in function to cliff overhangs; we are placing the boxes on trees, especially in places less accessible to poachers. We installed six boxes in 2010 and plan to continue this work.

\section{ACKNOWLEDGMents}

We are very grateful to all researchers who shared their data on Gyrfalcon nests, as well as to P. Romanov, T. Pröhl, and I. Ukolov for their assistance in the installation of nestboxes.

\section{Literature Cited}

CAde, T. J., P. Koskimies, ANd Ó. K. Nielsen. 1998. Falco rusticolus Gyrfalcon. Birds of the Western Palearctic Update 2:1-25.

Clum N. E., AND T. J. CADE. 1994. Gyrfalcon Falco rusticolus. In A. Poole and F. Gill (Eds.). The Birds of North America, no. 114. Academy of Natural Sciences, Philadelphia, and American Ornithologists' Union, Washington, DC, USA.

DANILOV, N. N., V. N. RYZHANOVSKIY, AND V. K. Ryabitsev. 1984. Birds of the Yamal Peninsula. Nauka, Moscow, Russia.

KALYAKIN, V. N. 1983. Raptor fauna and population status of rare species in Southern Yamal. Pages 120-124 in Ecology of Raptors: Proceedings of the $1^{\text {st }}$ Conference on the Ecology and Conservation of Raptors. Moscow, Russia (in Russian).

KALYAKIN, V. N. 1989. Birds of prey in ecosystems of the Far North. Pages 51-112 in Yu. I. Chernov (Ed.). Birds in Communities of the Tundra Zone. Nauka, Moscow, Russia (in Russian).

KALYAKIN, V. N. 1998. Birds of the Southern Yamal and trans-Ural polar region. Pages 94-115 in Materials to the Distribution of

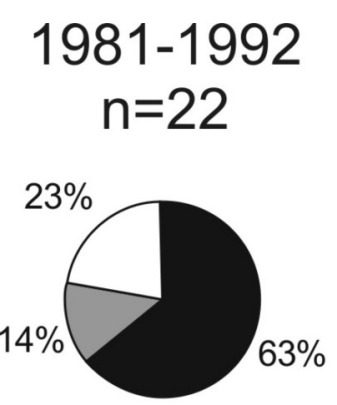

\section{5-2001 \\ $n=22$}

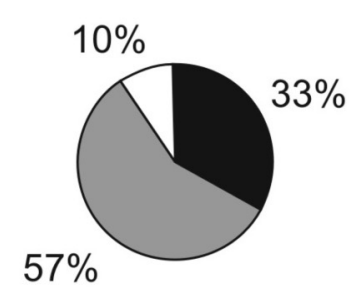

2005-2010

$n=17$

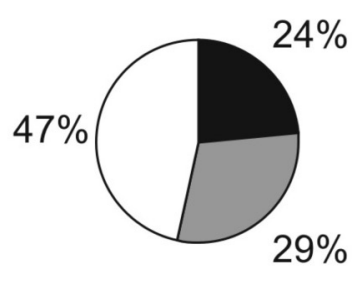

$\square 1 \square 2 \square 3$

Figure 4. Distribution of Gyrfalcon nests with respect to their sizes in different periods. Nest sizes: $1=\operatorname{large}(>80 \mathrm{~cm}), \quad 2=$ medium $(55$ $80 \mathrm{~cm}), \quad 3=$ small $(<55 \mathrm{~cm})$. 
Birds on Ural, Near-Ural Region, and West Siberia. Yekaterinburg, Russia (in Russian).

Kalyakin, V. N., AND V. G. VinOGRAdov. 1981. On Gyrfalcon nesting in the south of Yamal peninsula. Bulletin of the Moscow Society of Naturalists. Department of Biology 86(5):42-50 (in Russian).

Koskimies, P. 2006. Action plan for the Gyrfalcon (Falco rusticolus) in Europe. Pages 70-79 in P. Koskimies and N. Lapshin (Eds.). Status of Raptor Populations in Eastern Fennoscandia: Proceedings of the Workshop, November 8-10, 2005. Karelian Research Center of the Russian Academy of Sciences, Petrozavodsk, Russia.

KucheruK, V. V., Y. V. KovalevskiY, AND A. G. SuRbanos. 1975. Changes in the population of birds in Southern Yamal over the past 100 years. Bulletin of the Moscow Society of Naturalists, Department of Biology 80(1):52-64 (in Russian).

Mechnikova, S. A. 2009. Birds of prey on Southern Yamal: Features of breeding and dynamics of numbers. Ph.D. thesis, Moscow Pedagogical State University, Moscow, Russia (in Russian).

Mechnikova, S. A., AND N. V. KudRYAVtSEV. 2008. Long-term dynamics of numbers and productivity of the Gyrfalcon in the south of the Yamal Peninsula. Pages 128-129 in V. M. Galushin (Ed.). Research and Conservation of the Raptors in Northern Eurasia: Proceedings of the $5^{\text {th }}$ Conference on Raptors of Northern Eurasia. Ivanovo State University, Ivanovo, Russia (in Russian).

Mechnikova, S. A., M. S. Romanov, V. N. Kalyakin, AND N. V. KudRYAVTSEV. 2010. The Gyrfalcon, Falco rusticolus, in the Yamal Peninsula: Dynamics of brood size and nest size over the years 1973-2008. Russian Journal of Ecology 41(3):219-226 (in Russian).

Morozov, V. V. 2000. Ecological foundations and pathways of Gyrfalcon (Falco rustico$l u s$ ) in the tundras of European Russia. Russian Journal of Ornithology 95:3-11 (in Russian).

NiELSEN, Ó. K. 1999. Gyrfalcon predation on ptarmigan: Numerical and functional responses. Journal of Animal Ecology 68:1034-1050.

Oвsт, J. 1994. Tree nesting by the Gyrfalcon (Falco rusticolus) in the western Canadian Arctic. Journal of Raptor Research 28:4-8. Potapov, E. And R. Sale. 2005. The Gyrfalcon. T. \& A. D. Poyser, London, UK. 